of pneumonia, and great relief given to the patients. Now what is the modus operandi of such relief? Here are some of the theories: "By superseding one morbid action by another"; "that blisters act in a metastatic sense." Dr. Anstie held that the effect was gained by a stimulative action on the vessels of the part, and he suggested that it should be properly called "distant stimulation." We may say that blisters are supposed to act therapeutically either as derivants or reflexly through the nerves of the inflamed part. There is no doubt that stimulation of the sensory nerves of the skin leads to increased activity of the vasomotor centre, but in a case of pneumonia what is the action of a blister where the organ to be acted upon is 'remote, and where there is virtually little or no connexion between the parietal and visceral circulations? But that a 'blister applied to the chest in the active congestive stage of pneumonia gives relief $I$ have seen proved in many cases. This treatment is opposed to the advice given in all modern text-books. Dr. Anstie says $s^{1}$ that " the indiscriminate use of blisters in such cases as pneumonia, for example, in the hope of controlling the inflammation, is not only wrong, but almost ludicrous." But then many others besides me have seen the positive result of relief. 'Dr. George Johnson noticed that in pneumonia the exudation into the lung is speedily followed by a subsidence of the febrile excitement, otherwise a noxious product is thrown out of the circulation. He also believes that, if we can catch the disease in the stage of the initiatory fever before the exudation process has commenced, it is possible to prevent the pulmonary mischief by favouring exudation through other channels Dr. Lauder Brunton threw out the suggestion that blisters may act as a form of endermic administration of proteid matters altered in their passage from the vessels to the surface of the skin. May not this proteid matter exercise a destructive action on the microbe of pneumonia, and consequently cut the attack short, as I believe it does?

Toddington, Beds.

\section{A CASE OF IDIOPATHIC TETANUS ASSOCIATED} WITH DRINKING COLD WATER.

By SANDERSON MeLLOR, L.R.C.P., L R.C.S. ED., \&c.

THE comparative rarity of this serious affection induces me to ask you to give it publicity in your journal.

On May 12th I was asked to see as soon as possible a young man, J. $B-$, aged eighteen, as I was informed he was lying in bed and could not move. On arrival I found an exceedingly well developed and powerfully built youth lying on the bed in a position of complete lordosis. His lower jaw was tightly clenched against the upper, all the muscles of which were rigid and as hard as possible. He was ouite unable to separate his teeth, even to a quarter of an inch. The muscles of the abdomen were in a like condition. When I saw him he was able to draw up his legs in bed quite easily. He did not complain of any pain, and was quite unable to account for his present condition. Not the slightest sigu of a scratch or cut was to be found on any part of his body. He seemed fairly cheerful, and told me that he returned from work the night before, and, perspiring freely, went outside to the tank and drank about a pint of cold water. I suggested that a glass of ale would have done him more good, but he said he did not think so, as he was a total abstainer. I saw him again that night, when he was in much the same condition. On the following morning I found him in complate opisthotonus, the spasms of the voluntary muscles coming on at intervals in a most violent manner, and his face being singularly expressive of pain. This state of things continued without abatement for ten days, at the end of which time the disease seemed to be gradually wearing itself out-so much so that the masseters resumed their normal tone, and he was able to feed himself with a spoon. But dreading a long convalescence he was sent as an in-patient to the hospital, where he developed an attack of subacute rheumatism. He was in that institution five weeks, and on being discharged he presented himself at my surgery. The treatment consisted of large combined doses of biomide and chloral, tincture of Calabar bean, and opium, nutrient suppositories and enemata, also brandy mixture, which he sucked in between his teeth. I take it that this attack of acute tetanus was due to the pint of cold water taken when the body was overheated.

Weat Malling.
DEATH UNDER METHYLENE

By Edward Chamberlayne, M.B., C.M. Ed.

ON Monday, Aug. 3rd, I administered methylene to S. J. M- at the request of Mr. Colin Campbell of Upper. mill. She was about eight minutes before becnming unconscious. The methylene was administered slowly, and the Junker's inhaler removed from time to time. Besides the supply of air through the valve of the inhaler, there was a space, owing to falling in of the cheeks, easily admitting the tips of two fingers, on each side of the mouth between the mouth and the inhaler. All went on in a perfectly usual manner till about twenty minutes after the administration was begun, when she began to heave as if to vomit. The whole apparatus was at once removed, her head turned on one side, and her tongue pulled forward. A small quantity of frothy mucus was brought up. The heaving lasted about a minute and a half, after which she made several deep in. spirations of air. Seeing then that the respiration was fully established, and noticing the corneal reflex was present, the administration was resumed; two or three strokes of the hand-ball were given, when her face became livid and respiration ceased. Artificial respiration was instantly commenced, and injections of ether (six in all) were given, also three enemata of brandy. Her head was hung over the table, and Dr. Lawton Andrew of Mossley attended with a battery. Artificial respiration was kept up for an hour and twenty minutes, and it was then decided that the case was hopeless. Dr. Lawton Andrew and I were of opinion that the heart continued to contract for some time after respiration ceased; Mr. Campbell was doubtful. Four drachms of methylene were used out of the bottle, but of this probably a drachm had been wasted owing to its accidental overturning before my arrival. There was no post-mortem examination. The coroner's jury returned the verdict: "That the deceased was a fit subject for the administration of an anæsthetic; that the administration was skilfully performed; and that she died from mis. adventure.

In reference to the above Mr. C. Campbell writes as follows:--"I need add very little to Dr. Chamberlayne's accurate account of this lamentable occurrence. Mrs. M who had been a patient of mine for over seven years, consulted me, accompanied by a friend of hers, about her breast on Aug. 2nd. Finding undoubted 'cancer,' I recommended early removal, to which she willingly consented. I had completed the incisions around the breast, and nearly separated it from the thoracic walls, intending subsequently to open the axilla, when the breathing ceased. The head being allowed to fall over the table, the artificial respiration appeared to be very effective, so much so that the blueness disappeared from the lips and the face became life-like in colour. This encouraged us to persevere. I had frequently examined her heart, and believed it to be healthy." Stalybridge.

\section{A PILL LODGED IN THE RIGHT BRONCHUS.}

By Charles Steele, M.D., F.R.C.S.

I PRESCRIBED some pills containing iron for a lady about four weeks ago, which she took regularly three times a day with great benefit until Wednesday (Aug. 12th). Late on Thursday evening she called and said she was in such pain that she could not pass another night unrelieved. The pill which she took after dinner the day before did not seem to go the right way, and all her efforts to dislodge it failed. Before long pain set in in the front of her chest three inches below her right clavicle, and after a time a similar pain occurred in a corresponding spot behind, and deep breathing increased the suffering. She had been able to swallow fluids and solids all the time without difficulty. The last few hours she had expectorated with a cough, and whatever came up had the taste of the pill. Auscultation rendered no assistance. I laid her on her left side on a couch with her hips raised on cushions, and gave a few pats on her back, producing a sudden cough, and expectoration containing red spots like blood; this I put under a microscope; but there were no corpuscles, I diagnosed clearly that the pill had gone into the windpipe (probably owing to her drawing a breath when taking it), and that it had lodged in the lower bifurcation of her right bron. 